\title{
Form Follows Function: Advances in Trilayered Structure Replication for Aortic Heart Valve Tissue Engineering
}

\author{
Dan T. Simionescu², Joseph Chen ${ }^{3}$, Michael Jaeggli², Bo Wang ${ }^{1}$, Jun Liao ${ }^{1 *}$ \\ ${ }^{1}$ Tissue Bioengineering Laboratory, Department of Agricultural and Biological \\ Engineering, Mississippi State University, Mississippi State, MS 39762 \\ ${ }^{2}$ Biocompatibility and Tissue Regeneration Laboratory, \\ Department of Bioengineering, Clemson University, Clemson, SC 29634 \\ ${ }^{3}$ Department of Biomedical Engineering, Vanderbilt University, Nashville, TN 37235
}

Submitted April 2011. Accepted for publication December 2011.

\begin{abstract}
Tissue engineering the aortic heart valve is a challenging endeavor because of the particular hemodynamic and biologic conditions present in the native aortic heart valve. The backbone of an ideal valve substitute should be a scaffold that is strong enough to withstand billions of repetitive bending, flexing and stretching cycles, while also being slowly degradable to allow for remodeling. In this review, we highlight three overlooked aspects that might influence the long term durability of tissue engineered valves: (i) replication of the native valve trilayered histoarchitecture, (ii) duplication of the three-dimensional shape of the valve, (iii) and cell integration efforts focused on getting the right number and type of cells to the right place within the valve structure and driving them towards homeostatic maintenance of the valve matrix. We propose that the trilayered structure in the native aortic valve that includes a middle spongiosa layer cushioning the motions of the two external fibrous layers should be our template for creation of novel scaffolds with improved mechanical durability. Furthermore, since cells adapt to micro-loads within the valve structure, we believe that interstitial cell remodeling of the valvular matrix will depend on the accurate replication of the structures and loads, resulting in successful regeneration of the valve tissue and extended durability.
\end{abstract}

Keywords: heart valve tissue engineering, trilayered structure replication, microstructural fatigue, long term durability, tissue remodeling, bioreactor

*Corresponding author: Jun Liao, Tissue Bioengineering Laboratory, Department of Agricultural and Biological Engineering, Box 9632, Mississippi State University, Mississippi State, MS 39762. Phone: (662) 325-5987. Fax: (662) 325-3853. Email: jliao@abe.msstate.edu. Other authors: dsimion@clemson.edu; joseph.chen@vanderbilt.edu; mjaeggl@clemson.edu; bw428@msstate.edu 


\section{INTRODUCTION}

Aortic Valve Disease (AVD) is the third most common cause of cardiovascular disease affecting roughly 5 million people in the United States alone [1-3]. It is estimated that valve disease affects over $25 \%$ of people over 65 years of age [3]. Moreover, AVD is expected to become more prevalent in the coming years as the population life expectancy increases. It is estimated that the annual number of patients requiring heart valve replacement will triple from approximately 290,000 in 2003 , to over 850,000 by 2050 [4]. Thus, strategies to address AVD are bound to have a global impact.

Currently, the only effective treatment for AVD is total valve replacement. Present valve replacement strategies include use of mechanical heart valves, bioprosthetic heart valves, and allografts [5, 6] which offer excellent quality of life after implantation. Although all devices successfully restore the aortic root hemodynamics and facilitate ventricular remodeling, each strategy has significant limitations. Allografts are excellent choices; however, their supply is limited. Mechanical valves are biologically inert but susceptible to thromboembolic events and thus require lifelong anticoagulation medication. Bioprosthetic heart valves and allografts have poor long-term durability and are often subject to progressive leaflet deterioration and calcification. Finally, all replacement heart valves are relatively sensitive to infection and host tissue overgrowth which ultimately impair normal functioning and require surgical replacement. Taken together, current artificial valves offer excellent short and mid-term solutions that will require additional invasive surgeries to replace failed implants in the long term.

One major limitation of all the aforementioned valve replacement options is their inability to grow, repair, and remodel [7]. These characteristics are generally important for homeostatic maintenance of valve integrity under physiologic loads and especially relevant for the pediatric population. Current valve replacement strategies are effective in treating congenital valve disease. However, they do not accommodate the growing heart and thus, pediatric patients suffering from congenital valve disease require multiple invasive surgeries throughout their childhood. It is estimated that 20,000 children are born with congenital heart disease in the United States alone; thus, there is a great clinical need to develop valve replacements capable of restoring normal hemodynamics, while being non-thrombogenic and capable of repair, remodeling and growth with the patient [7].

Tissue engineering (TE) has emerged as a promising technology for the development of novel replacement valves that address the aforementioned shortcomings [5, 6, 8-13]. The general TE working paradigm involves scaffold fabrication, cell integration and bioreactor conditioning before implantation. The scaffold can be generated via many different methods but ultimately serves the purpose of providing a temporary matrix for seeded cells to secrete their own extracellular matrix (ECM) proteins. For tissue engineered heart valves (TEHVs), this matrix must be able to withstand the dynamic mechanical environment of the aortic valve (AV); therefore, scaffold fabrication requires careful consideration and design. Cell integration for TEHVs incorporates seeding of aortic valve interstitial cells (AVICs) inside the scaffolds and aortic valve endothelial cells (AVECs) onto the valve surfaces; other cells sources include endothelial progenitor cells and mesenchymal stem cells (bone-marrow derived) as they represent a clinically feasible strategy [14]. Once the cells are successfully integrated into the scaffolds, a bioreactor is necessary to condition the construct, allowing the cells to migrate, 
proliferate, and secrete ECM proteins and matrix-degrading enzymes as a normal homeostatic response to physiologic loads. This step is important as it prepares cells to deal with the 3-D loads immediately after implantation. This in vitro procedure may take 3-4 weeks to generate a conditioned construct that contains a large population of viable, functionally adapted cells. A more recent approach in TE involves the implantation of an unseeded scaffold. This approach is termed in situ TE and has shown promising results. By utilizing conjugated antibodies, Jordan et al. was able to show good cell accumulation onto the TEHV in an animal model [15].

Ultimately, the goal of TE constructs is to successfully restore hemodynamics with the ability to repair and remodel with time. Ideally, the original scaffold will slowly degrade and will be replaced by the naturally generated ECM. Recently, TEHVs have been an active area of research making much progress in the understanding of successful clinical implementation. However, there are still many issues that must be further addressed before TEHVs can become an effective treatment.

In this review, we will investigate novel methodologies proposed for scaffold fabrication and design of TEHVs. Furthermore, we will present some of our current research approaches that may inspire future investigations for TEHVs.

\section{AORTIC VALVE STRUCTURE-FUNCTION RELATIONSHIP}

For creation of successful TEHVs, it is necessary to have a clear view of the structure and function of native heart valves. We will focus on the aortic valve since among the four cardiac valves, the aortic valve is the one most diseased, replaced and researched. The aortic valve is located between the left ventricle and aorta and functions to ensure unidirectional blood flow and to prevent regurgitation of blood into the left ventricle. It consists of three semilunar cusps attached to the inner wall of the aorta residing within the sinuses of Valsalva. The cusps or leaflets are the main functioning components of the aortic valve. These delicate structures endure the dynamic opening and closing of the valve 40 million times a year and more than 3 billion times during an average lifetime [16, 17]. The highly dynamic environment of the valve illustrates the complex function of the leaflets and pinpoints the importance of processes involved in maintaining healthy valve function.

The aortic valve leaflet is composed of three layers: fibrosa, spongiosa, and ventricularis [13]. The fibrosa layer is located closest to the outflow area and is composed of densely aligned collagen fibers; this layer is responsible for the mechanical strength and stiffness of the leaflet. The ventricularis is located closest to the left ventricle and is largely comprised of elastin fibers which play an important role of extending and recoiling during diastole and systole, respectively. The middle layer, spongiosa, is mainly comprised of proteoglycans and glycosaminoglycans (GAGs) which act as a cushion and bears the applied stresses of valve function. This tri-layered structure, each layer being composed of different matrix elements, is unique to the cardiovascular system. The three layers are structurally continuous and work in conjunction with one another to fully satisfy the mechanical demands involved in normal valve function.

Although the structural design of the leaflet makes it mechanically suitable for opening and closing, the structure consistently accumulates micro-damages and therefore requires continuous repair. The repair mechanisms are carried out by the resident cells of the aortic leaflet which include AVECs and AVICs [18]. AVECs form 
a monolayer on the surface of the AV leaflet and are believed to regulate vascular tone, inflammation, thrombosis, and remodeling. Similar to endothelial cells in other segments of the cardiovascular system, AVECs form a layer around the leaflet which acts as a selective barrier for various components in the blood. AVICs are a heterogeneous cell population residing within the AV leaflet and serve to maintain tissue homeostasis and structural integrity. AVICs continuously secrete collagen types I and III, glycosaminoglycans (GAGs) and other matrix components as well as matrix metalloproteinases (MMPs), their inhibitors (TIMPs), and other matrix degrading enzymes such as GAG-degrading enzymes that mediate remodeling [19-21]. AVICs exhibit a dynamic phenotypic spectrum ranging from quiescent fibroblast-like cells (characterized by expression of vimentin, fibroblast surface antigen and low expression of alpha-smooth muscle cell actin and MMP-13), to activated AVICs, assimilated as myofibroblasts (characterized by proliferation, migration, high expression of vimentin, alpha-smooth muscle cell actin and MMP-13) [13, 22-25]. The activated AVICs are considered the pivotal cells that control valve structure and function [25]. Interactions among mechanical forces, valvular cells and the extracellular matrix influence remodeling potential and therefore durability of heart valves. Duplication of these structures and interactions in a man-made device is truly bioengineers' dream and has the potential to provide tremendous clinical benefits.

\section{THE IDEAL TISSUE ENGINEERED HEART VALVES (TEHV)}

Generally, in order for a TEHV to successfully function in vivo, it must be biocompatible, durable, and also have the ability to remodel and grow. Design and fabrication of TEHV scaffolds must carefully consider these variables. Biocompatibility is crucial for successful TE and is often dependent on scaffold material [26, 27]. Synthetic and biological materials must thus be evaluated to determine biocompatibility before scaffold design. Decellularized xenografts often encounter biocompatibility issues because of their animal origin and thus need to utilize various decellularization solutions to remove foreign antigens in order to prevent immune responses. Durability considerations are important because of the highly dynamic environment of the aortic valves [17]. The mechanical integrity of the scaffold must not be compromised during the implantation procedure or shortly thereafter. Different scaffold materials exhibit different mechanical properties; therefore scaffold selection requires in vitro testing of mechanical properties. Manipulation of the mechanical strength of materials can be carried out through various techniques such as cross-linking of acellular tissues and general design schemes using polymers.

Cell integration and remodeling of the scaffolds are of utmost importance to successful TEHV because cell viability and state of activation determine the continued function of the TEHV in vivo. The goal is not simply to seed cells onto a scaffold; rather, it is necessary for the cells to be viable and functional, positioned in the right tissue niche and able to maintain normal tissue homeostasis. Recent studies have indicated that cell function is closely modulated by its substrate environment [28-30]. Therefore, imitating the structural makeup of the native leaflet could improve cell retention and function. The ideal TEHV must be able to be compatible with the in vivo environment, be durable enough to withstand the dynamic mechanical environment, 
and create an environment that promotes cell attachment, integration and function. In the following sections, we will discuss current studies that represent the strides made toward fabrication the ideal TEHV scaffold.

\section{CELL SOURCE AND SEEDING}

The cell is clearly an important contributing factor to successful TE. Although the resident cell, AVICs and AVECs, are a logical choice for seeding TEHVs, they may not be economical in the clinical setting. Therefore, other sources must be considered for TEHVs. Bone marrow-derived stem cells (BMSC), umbilical cord-derived stem cells (UCSC), and blood derived endothelial progenitor cells (BEPCs) are a few attractive options for cell source [31-35]. BMSCs are a promising cell source because they can be obtained without surgical interventions, and can be set up as a routine clinical procedure. Hoerstrup et al. used BMSCs and demonstrated viable tissue formation with characteristic extracellular matrix proteins [31]. UCSCs also present an attractive option as a cell source for TE applications. These cells are easily attained by isolation via intact donor samples from newborns. UCSCs have been shown to have excellent growth potential and production of extracellular matrix in vitro. BEPCs are also easily attainable as they are circulating in the blood and can be isolated in many minimally invasive manners [36]. BEPCs have been used to endothelialize scaffold prior to implantation to reduce coagulation and inflammatory complications [32].

Cell seeding strategies for TE are well summarized in a review by Villalona et al. [37]. In general, there are two main types of approaches for cell seeding: static seeding and dynamic seeding. The most widely used techniques are static seeding which involves the pipetting of a cell suspension directly onto the scaffold. Although simple, this method has many disadvantages including difficulty in uniform seeding, poor seeding efficiency, and poor proliferation [38]. Other static approaches include seeding with biological glues. This method allows the cells to stay in close contact with the scaffold thereby improving seeding efficiency [39]. Dynamic seeding methods are designed to address the limitations of the static methods. Dynamic methods include perfusion systems, rotational systems, vacuum systems, electrostatic seeding, and even magnetic seeding methods [40-46]. These methods possess many advantages and have been combined to yield desirable results as well. However, there has yet to be an established method for optimal cell seeding of TE constructs. Many groups are currently developing new strategies to provide adequate cell seeding for TE constructs.

There has been a push towards in situ TE which involves minimal to no in vitro seeding and aims to utilize the in vivo environment for cell accumulation. Jordan et al. showed that conjugating their scaffold with an antibody was all that was necessary to get endothelialization of their scaffold in vivo [15]. This study presents new questions to the TE paradigm and represents an area for further investigation.

\section{SCAFFOLD MATERIALS}

\subsection{Decellularized Allografts and Xenografts}

Acellular tissues have been widely investigated as a scaffold material for TE applications [47-56]. The advantage of this technique is that the overall structural composition of the leaflet is retained; however, the decellularization process alters some 
of the ECM components and leads to weaker mechanical properties and decreased durability [57, 58]. The conventional route to overcome this limitation has been utilizing cross-linking agents to increase mechanical strength and durability after decellularization [26, 59-61]. However, many cross-linking agents such as glutaraldehyde are toxic to cells and therefore not ideal for TE applications. Efforts have also been focused on detoxifying harmful cross-linking agents as well as proposing new agents to enhance acellular tissue mechanics [62, 63]. The Simionescu group proposed use of penta-galloyl glucose (PGG), a naturally derived, non-toxic polyphenol, to stabilize acellular scaffolds [59, 64, 65]. The PGG-treated scaffolds exhibited many desirable properties and thus PGG is considered a promising stabilizing agent for decellularized scaffolds. Other approaches utilize decellularization protocols that are less harsh and induce less damage to the ECM. Booth et al. investigated the effects of various chemicals (sodium dodecyl sulfate, Triton X-100, sodium deoxycholate, MEGA 10, TnBP, CHAPS, and Tween20) on decellularization and concluded that a certain combination of the chemicals led to an optimal result which allowed for retention of major structural proteins [66].

Due to the scarcity of allografts, decellularization of xenogeneic valves (e.g., porcine valves) also attracted considerable research interest [67, 68]. When acellular xenogeneic valves are used as scaffolds, the challenges are not only the complete removal of cells and cell debris, but also the thorough elimination of the alpha-Gal epitope, the most potent xeno-antigen responsible for transplant rejection [52, 69-72]. Despite the fact that optimized decellularization protocols apparently maintained the 3-D ECM arrangement, some cell-seeded scaffolds encouraged calcification and thickening upon implantation [73], indicating the need for more biological tests including resistance to inflammation and calcification to be added to the armamentarium of scaffold selection tools.

There have been some exciting studies illustrating the potential of xenogeneic tissues for TE. Recently, Tedder et al. suggested use of acellular porcine pericardium for construction of TEHVs; the scaffolds exhibit outstanding mechanical properties and can be fashioned into cusp-shaped structures that mimic the human aortic valve [65, 74]. Matheny et al. also demonstrated the feasibility of utilizing small intestinal submucosa (SIS) as a potential scaffold for TE [75]. This study revealed successful endothelialization of the SIS construct placed in the pulmonary position.

The search for the ideal decellularization procedure continues [76]. It is anticipated that, ultimately, a combination of acceptable decellularization methodology and crosslinking or stabilizing agents would lead to a promising scaffold for TEHVs. Present questions include the following: Which decellularization process is the most suitable? What is the best method to retain acellular valve mechanics and at the same time create good porosity for cell reseeding/infiltration? What is the appropriate seeding method for successful cell infiltration?

\subsection{Polymeric Scaffolds}

Polymeric scaffolds can be derived from biological or synthetic sources, each having advantages and disadvantages. Biological polymers possess intrinsic cell compatibility as most are structural components familiar to cells, but also tend to be mechanically weak and difficult to manipulate. Synthetic sources are easily tailored and can be reproduced 
readily, allowing for novel structural designs that can control mechanical properties, surface topography, and porosity. Some limitations include uncertainties regarding the degradation rate and products as well as cell compatibility. A short description of studies investigating the feasibility and optimization of polymer scaffolds for TEHVs follows.

\subsubsection{Biological Sources}

For biological polymer scaffolds, collagen, fibrin, and hyaluronic acid have been actively investigated [27, 77-87]. Many of the studies have shown acceptable cellular growth into these materials and desirable degradation control, but these scaffolds are too weak for the aortic valve environment and require more development to increase their mechanical characteristics.

Collagen comprises a large percentage of the dry weight of the aortic valve leaflet and therefore is a logical choice for TEHV applications [88]. Flanagan et al. utilized collagen gel constructs for TE applications and showed good growth of AVECs and AVICs; however, the mechanical strength of the construct was not thoroughly investigated [87]. Shi et al. used collagen fiber-collagen gel composites to manipulate the mechanics of their scaffold and enhance its mechanical properties to a stiffness of 5 MPa and an extensibility of $14 \%$ [83].

Fibrin is a biodegradable, biocompatible matrix protein involved in wound healing and can be produced from a patient's blood and therefore does not initiate inflammation, tissue necrosis, or fibrosis [79, 89-91]. Jockenhoevel et al. tested molded fibrin gels as potential scaffolds for TE [79], and showed their good cell growth and ECM production capability, but poor mechanical stiffness and scaffold shrinkage. Grassl et al. investigated the response of neonatal aortic smooth muscle cells (SMCs) in the presence of fibrin and collagen [92], and found that fibrin was able to induce ECM production, a desirable trait for TE.

Hyaluronic acid (HA) makes up $90 \%$ of the total GAGs in human heart valves, thus making it a possible candidate for TEHV scaffolds [20, 93]. HA does not initiate immune or thrombogenic events and also possesses viscoelastic properties [5, 94]. Masters et al. demonstrated that HA can be cross-linked into a hydrogel, and HA degradation products generated a four-fold increase in matrix production by VICs cultured for 6 weeks [94]. Flanagan et al. demonstrated the feasibility of fibrin scaffolds through dynamic conditioning [95] and also conducted a 3 month in vivo study in sheep model revealing cell viability and remodeling [96]. However, an insufficient leaflet structural profile led to a decrease in functionality.

In general, biological materials possess many desirable characteristics but are often limited by their xenogeneic origin or poor mechanical properties of individual components [5, 97]. Further studies into fabrication techniques are necessary to improve their mechanical properties.

\subsubsection{Synthetic Sources}

Synthetic scaffolds are easily reproduced and manipulated by various fabrication techniques. Poly(glycolic acid) (PGA), poly(lactic acid) (PLA), poly(caprolactone) (PCL) and poly(hydroxyalkanoate) [98] are some commonly studied polymers for TE $[31,99]$. Each polymer possesses certain properties that can be altered with the 
combination of other polymers. Utilizing blends and copolymers such as poly (4-hydroxybutyrate) (P4HB) allows development of materials with very precise characteristics. Shinoka et al. pioneered TEHV designs in the late 1990s and investigated PGA and PLGA nonwoven scaffolds in a sheep model [100-102] with favorable results, but the constructs became thicker and stiffer probably due to inflammation [100]. More recent efforts have been on enhancing cellular integration and regulating mechanical properties. Cell infiltration has been a concern for these nonbiological material; however, significant progress has been made. Ozawa et al. [103] and Nuttelman et al. [104] demonstrated that seeded cells could produce ECM proteins and remain viable, but proliferation rates were not optimal. In vitro conditioning studies have shown enhanced cell viability and ECM production on polymer scaffolds $[105,106]$. Structural design of the scaffold is important to the improvement of cell integration and mechanical properties. Many studies have investigated various fabrication techniques to generate novel structures for TE applications [97, 107-112]. Porous designs [99, 113, 114], nonwoven and woven designs [31, 36, 99-102, 105], and electrospun designs [98, 115-118] have been studied.

As techniques and approaches become better established, detailed design issues need to be addressed. Most scaffolds have yet to consider the trilayered structure of native leaflets. The structural environment is important to optimal cell function as well as mechanical properties [96]. Recent studies reveal that VICs are sensitive to their substrates, implying that the structural components to which cells attach could be important for maintaining normal cell function [28]. Furthermore, a trilayered scaffold can preserve the mechanical duties of each layer thus reducing added stresses and strains. The remainder of this review will discuss new insights and future direction for trilayered scaffolds.

\section{TRILAYERED STRUCTURE IN NATIVE LEAFLETS: IMPLICATION FOR TEHVs}

Internal shear is believed to be an important factor underlying valvular bending properties [119-121]. In both systolic and diastolic phases, shear movement develops in native aortic valve leaflets when the fibrosa, spongiosa, and ventricularis layers slide and readjust their positions to minimize the internal stresses [121]. In the absence of optimal shear properties, tissue buckling will take place in response to compression caused by bending deformation [121]. Apparently, in the native aortic valve leaflet, the existence of the spongiosa as a stress-mitigating cushion layer renders optimal leaflet bending behavior and reduces the likelihood of collagen fiber buckling and thus fatigue accumulation.

The effectiveness of nature-designed trilayered structure in valvular flexure can be evidenced by the following study, in which we investigated the flexural responses at microstructure-level in the native, decellularized $(0.1 \%$ sodium dodecyl sulfate [SDS] treatment), and glutaraldehyde fixed $(0.625 \%$ Glut $)$ porcine aortic valve leaflets. Briefly, a tissue strip $(15 \mathrm{~mm} \times 5 \mathrm{~mm})$ was cut from each of the native, decellularized, and glutaraldehyde fixed groups along the circumferential direction. The leaflet strips were then folded into a "U" shape towards the fibrosa side in a phosphate-buffered saline (PBS) bath. The "U" shape leaflet strips were then 
clamped at two edges and fixed with $4 \%$ glutaraldehyde for later histological study. The Movat's pentachrome staining and polarized light imaging showed that various microstructural responses existed in the native, decellularized, and glutaraldehyde fixed leaflets (Figure 1). We found that the native leaflet was able to well cope with the extreme flexure with the coordination of the three layers. As revealed by

(a)

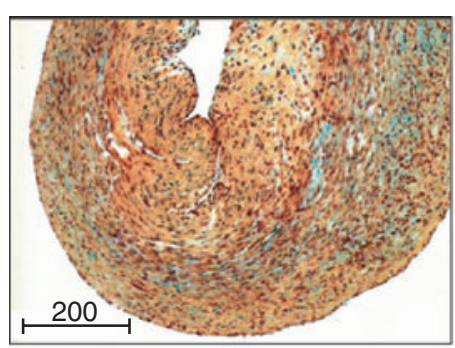

(c)

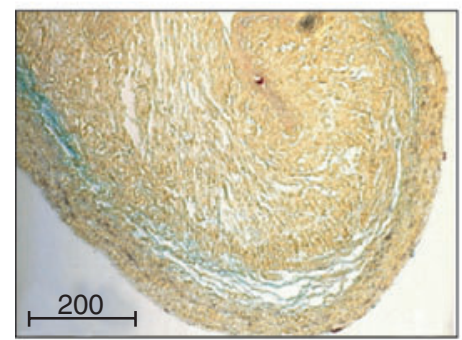

(e)

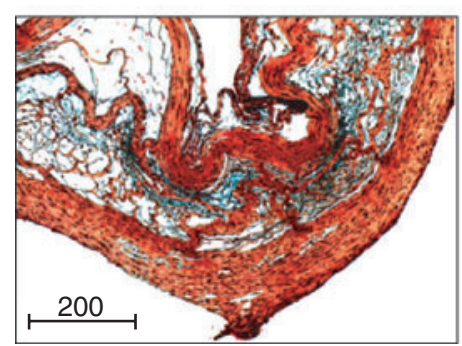

(b)

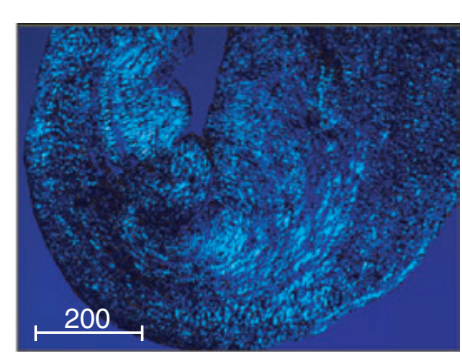

(d)

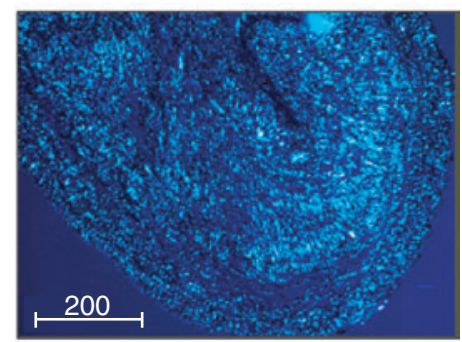

(f)

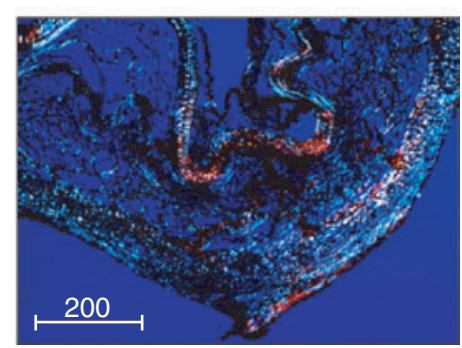

Figure 1. (a) Movat's pentachrome staining and (b) polarized light imaging of the native porcine aortic valve leaflet; (c) Movat's pentachrome staining and (d) polarized light imaging of the decellularized ( $0.1 \%$ SDS treatment) aortic valve leaflet; (e) Movat's pentachrome staining and (f) polarized light imaging of the glutaraldehyde fixed $(0.625 \%$ Glut $)$ porcine aortic valve leaflet. Sample preparation: The leaflet strips were folded into a "U" shape towards the fibrosa side in a PBS bath; the "U" shape leaflet strips were then clamped at two edges and fixed with $4 \%$ glutaraldehyde for histology. Scale bar unit: $\mu \mathrm{m}$. 
histology, the fibrosa layer was able to readjust the fiber crimps to compressive stress without causing fiber buckling; the ventricularis layer experienced uncrimping of fibers due to tensile stress; and the spongiosa seemed to smoothly mediate the layered structure across the leaflet thickness (Figure 1-a, b). For the decellularized leaflet produced by $0.1 \%$ SDS treatment, the trilayered structure was found relatively preserved; however, microstructural disruptions such as collagen crimp organization and loss of GAGs were observed [122]. It was thus understandable that the decellularized leaflet was able to cope with the extreme flexure relatively well, i.e., no noticeable fiber buckling in the fibrosa (compressive region), but overstretch of fibers observed in the ventricularis (tensile region) (Figure 1-c, d). For the glutaraldehyde treated leaflet, the crosslinking stiffened the whole fiber network, and the spongiosa layer lost the cushion functionality. Consequently, the lack of a functioning trilayered structure caused difficulty in coping with the extreme flexure introduced by the "U" shape folding; notably, serious fiber buckling was revealed by both histological and polarized light images (Figure 1-e,f).

We thus believe that the design of engineered composites should include mechanisms of coping with the complex bending deformations. This is important as the scaffolds are exposed to such loads immediately after implantation and thus their durability will be tested in every cardiac cycle thereafter.

\subsection{Single-layered Design versus Trilayered Structure Design}

Due to the challenges associated with the fabrication a trilayered scaffold, most TEHVs are based on a single layer design. Potential of tissue remodeling has been shown in a few in vivo studies [99, 113, 123]. Sodian et al. [113] implanted TEHV fabricated from polyhydroxyalkanoate scaffolds (pore size 180 to 240 microns) seeded with vascular cells into pulmonary position of a lamb model. Sodian et al. mentioned that histology demonstrated "laminated fibrous tissue with predominant glycosaminoglycans as extracellular matrix" [113]. In another study, Hoerstrup et al. [123] seeded poly-4-hydroxybutyrate (P4HB)-coated PGA constructs with vascular myofibroblasts and endothelial cells, conditioned the TEHV in a pulsatile bioreactor for 14 days, and implanted the TEHV into pulmonary position of a lamb. It was shown that after 16 weeks of implantation, TEHV leaflet evolved into "layered cellular fibrous tissue, which is denser near the outflow surface" [123]. These studies indicate that scaffold remodeling is possible and that physiologic loading leads to layering of de novo synthesized tissues.

In short, cyclic bending may cause harsher internal shear and buckling in single layer TEHV, and thus long-term durability will be questionable. If it turns out that valve loading during cardiac cycling is able to remodel a "single-layer" scaffold into "three layers" after implantation, it is possible that valve regeneration is feasible in a bioreactor or in vivo. There are still critical issues to be addressed such as whether the TEHV remodeling will be fast enough before destructive buckling and damage occur, how robust the adopted laminated structure will be, and how it will benefit long-term fatigue resistance. Design of a very robust trilayered structure before implantation might therefore offer a better solution. Two approaches to achieving this design are discussed in the following sections. 


\subsection{Trilayered Design in Acellular Valves: Benefits and Challenges}

One option of appraising trilayered designs is using acellular aortic valves. Recently, da Costa et al. [124] reported a study evaluating the early and midterm results of decellularized aortic valve allografts (DAVA, 0.1\% SDS treatment) as an aortic valve replacement (41 patients, implanted between 2005 and 2010). They observed that the early and midterm results demonstrated stable structural integrity, low rate of calcification, and adequate hemodynamics of the valves, even in the absence of seeded cells [124]. The reported clinical mid-term results are very promising, possibly indicating that preservation of the trilayered structure translates into aortic root functionality and fatigue resistance. As reported by Liao et al., 0.1\% SDS treatment of aortic valve leaflets appeared to maintain critical mechanical and microstructural properties of the scaffolds [122]. The $0.1 \%$ SDS treatment preserved the gross morphology, leaflet dimensions, and trilayered structure, with a layered structure similar to the native leaflet. However, microstructural disruptions such as collagen crimp organization and increased extensibility along the radial direction were also observed [122]. The milestone study by da Costa et al. [124] will likely reignite the enthusiasm for TEHVs that was dampened by the failure of the first "tissue engineered" decellularized porcine heart valve (Synergraft) [57].

In a DAVA sample obtained from a reoperation after 18 months, a few cells with fibroblast appearance were believed to migrate superficially into the aortic media [124]; thus the major challenge associated with acellular valves is insufficient cell reseeding/infiltration due to their dense ECM network. For example, in an in vitro study, Rieder et al. [52] compared recellularization potential of acellular porcine valves prepared using various treatments, and observed poor recellularization of SDS and trypsin treated valves, with only tert-octylphenyl-polyoxyethylen/SDS combinations showing some potential for human cell recellularization. Lichtenberg et al. [125] showed that a complete endothelialization of decellularized scaffolds can be achieved using a bioreactor that mimics physiological circulating condition. Karim et al. [68] also showed that in a bioreactor, good recellularization took place on the surface of the decellularized porcine AV, with efficiency of adherence higher with myofibroblasts than with ECs. However, the main challenge still lies in the complete recellularization with valve interstitial cells. Liao et al. observed using SEM that acellular collagen network in leaflets treated with SDS, trypsin, or Triton X-100 all showed a dense fiber network that was lack of interconnected pores, suggesting a challenge for cell infiltration [122].

In summary, naturally preserved trilayered structures such as those found in acellular aortic valves are excellent mechanical alternatives; however, these scaffolds are too dense to be populated with cells. The absence of valvular interstitial cells in valve scaffolds may constitute a threat for the long-term durability of the constructs due to lack of tissue remodeling, maintenance and repair potential.

\subsection{Trilayered Designs based on Collagen Scaffolds}

Our current approach to creating a viable trilayered aortic valve prosthesis was described by Tedder et al. [74]. Briefly, fibrous collagen scaffolds to be used as fibrosa and ventricularis layers were created from decellularized porcine pericardium. Decellularized pericardium exhibits excellent mechanical properties and has been 
shown earlier to be a promising substrate for heart valve tissue engineering [126]. Porous spongiosa scaffolds were also created from decellularized and elastase-treated porcine pulmonary arteries. Fibrosa and ventricularis layers were then stabilized with PGG, a collagen stabilizer that reduces biodegradation without chemically crosslinking collagen. Trilayered scaffolds composed of one layer of spongiosa entrapped between two layers of collagen showed good shearing properties that approximated those of porcine aortic valves. Silicone molds of porcine aortic valves were then made and used to shape the valve construct. For bio-functional testing, a spongiosa scaffold was seeded with human-bone-marrow-derived stem cells inserted between the two fibrous pericardial layers and glued together to finalize the construct. The resulting valve-shaped TEHV proved to be biocompatible and able to immediately function under physiological pressures exerted by a heart valve bioreactor [74]. Moreover, the seeded stem cells changed their phenotype into cells resembling valvular interstitial cells in the absence of any added growth hormones or other chemical differentiation stimuli. These results suggest that mechanical loads specific to the aortic valve (stretching, bending, and extension) alone can induce stem cell differentiation into desired valve cell types. Based on the notion that "form follows function", current research is underway to develop a patient-tailored valve molding process with the intent of reducing patient-prosthesis mismatch. Data obtained from computed tomography will be processed digitally to produce an exact threedimensional model of each patient's heart valve anatomy. This model will then be printed on a rapid prototyper as a mold. The mold will be used to shape the trilayered scaffold for an exact patient fit.

\section{BIOREACTOR CONDITIONING OF TEHVS}

As mentioned above, bioreactor conditioning of TEHV constructs prior to implantation is useful for ensuring the integrity of the valve under physiological stresses and for inducing phenotypical changes in resident cell populations. Hoerstrup et al. conditioned a cell-seeded, synthetic, tri-leaflet valve in a pulse duplicating bioreactor prior to implantation in lambs [123]. These valves showed similar mechanical properties and ECM production to native tissue. However, there was no development of a tri-layered structure [123]. Another use of bioreactor testing is for identifying and addressing structural faults in valve design prior to lengthy animal studies. Wang et al. tested a novel polymer trileaflet heart valve in a sheep model [127]. The new valve design failed due to leaflet cracking and tearing. Bioreactor testing prior to an animal study would likely have exposed this design's fault. Mechanical stimuli have been shown to travel through ECM and cells and induce a variety of cellular responses [128]. More recently, mechanical stimulation alone has been shown to affect stem cell differentiation [129]. Specific mechanical forces that have been shown to induce differentiation include shear 
forces [130], compression [131], and stretch [132]. Heart valves are exposed to a wide variety of forces at every beat of the heart. We anticipate that bioreactor conditioning of stem-cell-seeded trilayered valves in a pulsatile flow bioreactor (Figure 2) will support stem cell differentiation and induce the onset of construct remodeling as a response to the appropriate loads [64]. We believe that partially remodeled valves stand a better chance of long-term survival after implantation.

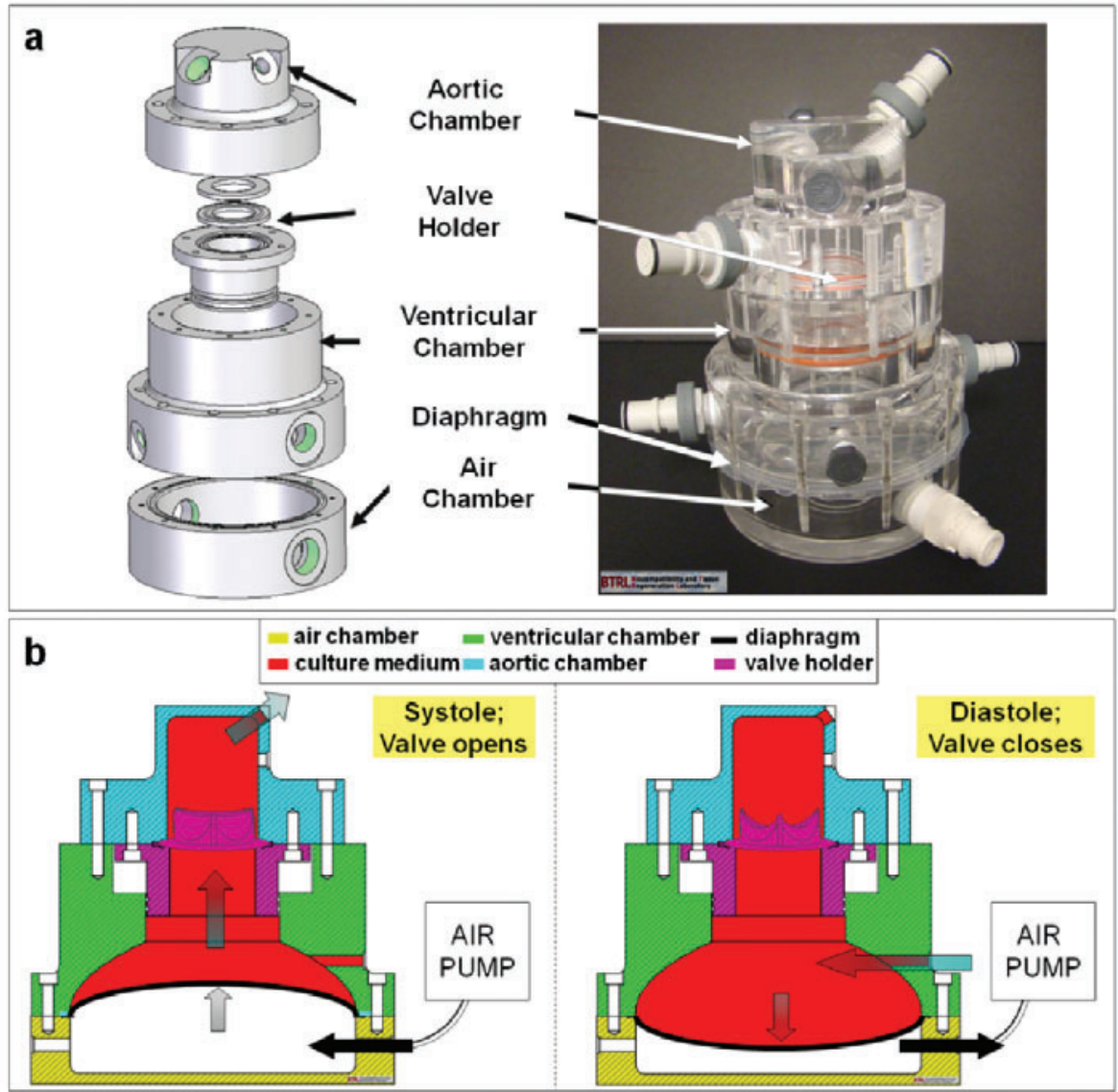

Figure 2. (Continued) 


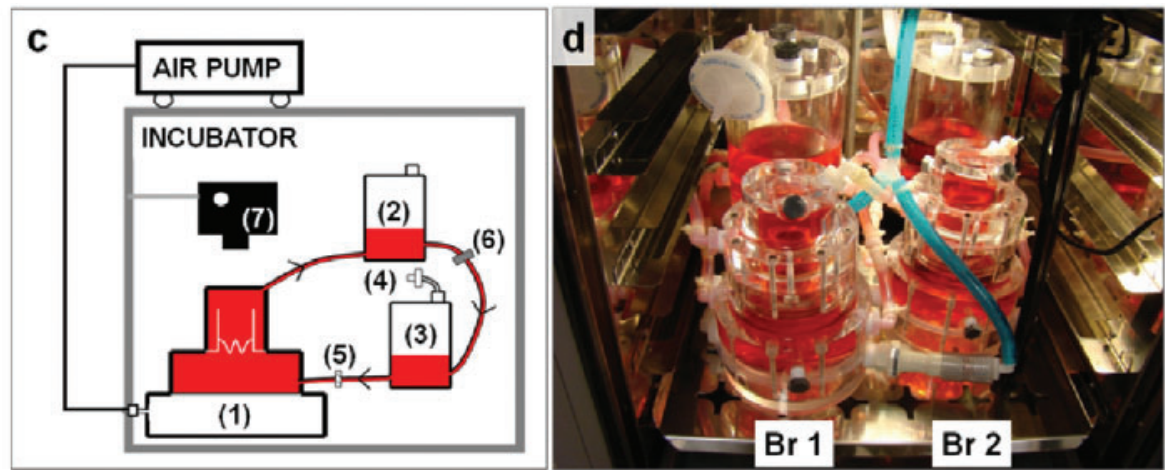

Figure 2. Heart valve bioreactor and conditioning system. (a) computer-aided design (left) and manufactured heart valve bioreactor (right) showing the four main components. A transparent silicone membrane diaphragm is mounted between the air chamber and the ventricular chamber. (b) Air and media flow through the system during systole (left) and diastole (right). Color coding aids identification of the components, and black arrows indicate direction of air and media flow. (c) Schematic overview of the entire conditioning system: a three-chambered heart valve bioreactor (1), an optional pressurized compliance chamber (2), a reservoir tank (3) with sterile filter (4) for gas exchange, one-way valve (5), pressure-retaining valve (6), a webcam (7), and a ventilator pump (air pump). The entire setup fits within a standard cell culture incubator. (d) Two identical bioreactor systems $(\mathrm{Br} 1$ and $\mathrm{Br} 2)$ with endothelial cellseeded, functioning valves inside an incubator; the bioreactors are in the front row while their corresponding reservoirs are in the back row. The webcams normally mounted onto the top viewing windows of the aortic chamber have been removed to reveal bioreactor details. Figure reproduced with permission [64].

\section{FATIGUE, DAMAGE, AND LONG-TERM DURABILITY OF TEHVS}

The current TEHV efforts are still focused on fabrication of a viable heart valve construct which is biomechanically and structurally robust, being able to perform in the dynamic environment of aorta, as well as with effective cell reseeding that can elicit tissue remodeling and adaptation. As we discussed above, there are many approaches and design philosophies in TEHVs. Other than optimizing scaffolds and cell reseeding of a chosen design, it will be very beneficial to address long-term durability issues at the designing stage. For instance, it is important to understand the potential fatigue and damage mechanisms of a specific TEHV design, and how different designs will affect long-term durability of TEHV differently. Without solid bioengineering considerations in long-term durability of TEHV, one can only rely on the expectation that "tissue remodeling and adaption" will occur after implantation, 
which is a trial-and-error approach with numerous potential risks. A flawed design will be an inherent risk factor and likely cause TEHV failure along with a possibility of the accumulation of structural damages surpassing the repairing capability of integrated cells. However, there is still lack of knowledge on mechanisms of TEHV fatigue, damage, and repair; there is also absence of data on long-term durability of TEHVs both in vivo and in vitro.

Due to decades of experience in clinical applications and research in allograft and bioprosthetic heart valves (BHVs), a good amount of knowledge has been obtained on the damage pattern and mechanisms of the structural deterioration of those valve implants. We believe that applying the knowledge gained from allograft and BHV durability tests might shed light on damage mechanisms and durability of TEHVs. Sabbah et al. showed that in porcine BHV leaflets, the sites of calcification and tissue disruption have close association with the sites of high stress concentration [133]. Haziza et al. studied pure leaflet tear failures in both porcine and pericardial BHVs (in the absence of calcification), and reported that damages often took place at sites with intense stress concentrations, for instance, at the mounting sites or portions of leaflet that experienced higher bending stresses [134]. The glutaraldehyde-fixed single-layer pericardium and porcine leaflet demonstrated inferior bending behavior due to either lack of trilayered structure or poor internal shear resistance caused by glutaraldehyde fixation [121]. These observations suggest the importance of the design of the trilayered structure in TEHVs that closely mimics the native heart valve leaflet (fibrosa, spongiosa, and ventricularis), with a goal to eliminate potential structural damages (likely tissue buckling and tear) induced by cyclic fatigue.

Grabenwoger et al. [135] compared BHVs fabricated from autologous pericardium and heterologous pericardium (average implant period was $33 \pm 8$ months). The autologous pericardium valves (briefly immersed in glutaraldehyde) were found to have very good biocompatibility, evidenced by the absence of calcium deposits, macrophages, and the presence of endothelialization; however, severe disintegration of collagen fibers was observed, indicating lack of fatigue resistance due to inadequate crosslink stabilization [135]. On the other hand, heterologous pericardium valves failed due to calcification resulted from low biocompatibility, but exhibited a superior preservation of collagen network [135, 136]. Aortic valvular allografts, due to nonviability, were also reported to undergo progressive noncalcific structural degeneration such as tearing, sagging, or retraction, with disruption of the normal valve architecture [137]. The above studies [135-137] suggest that, even with good biocompatibility and optimal structure design in heart valve replacements, without cellular maintenance such as damage repairing and tissue remodeling/adaptation, structural damage at the ultrastructural level will likely accumulate with time and impair the long-term durability of TEHVs. In an in vitro fatigue mechanism study, Liao et al. [138] found that the fatigue pattern of the acellular leaflets included an unfolded and thinned morphology, straightening of the locally wavy collagen fiber structure, and disruption of elastin network. Although the durability of the acellular leaflets cannot be extrapolated from this type of in vitro fatigue mechanism, this mechanistic study [138] 
reveals that, in the absence of cellular maintenance, decellularized valve leaflets experience structural deterioration in cardiac cycling $(\sim 2.4$ million cardiac cycles) due to lack of exogenous stabilizing crosslinks as well as irreversible and cumulative structural disruption. A well-designed cell integration, which reflects the heterogeneous functional roles of valvular cells (VICs and VECs), is thus of great importance to the long-term durability of TEHVs [74, 139].

\section{CONCLUDING REMARKS}

Many efforts have been made in the last 50 years to develop the ideal heart valve substitute that will last a lifetime. The task is formidable because of the particular hemodynamic and biologic conditions present in the native aortic heart valve [140]. Tissue engineering an aortic heart valve requires extensive interdisciplinary efforts that combine scaffold development, matrix chemistry and biochemistry, biomechanical analysis, cell biology, mechanotransduction, bioreactor engineering, and animal studies.

The existence of a trilayered structure in the native aortic valve is an overlooked aspect of heart valve physiology and should be considered in future tissue engineering endeavors. The current review shows that single layered scaffolds have a low chance of success because of the daunting mechanical requirements specific to the aortic valve. However, even the best trilayered scaffolds might not resist billions of the repetitive bending, flexing and stretching cycles in the absence of viable cells capable of repairing and remodeling the scaffolds on a sustainable basis. Thus, equally important are cell integration efforts focused on integrating the right number of cells of the appropriate cell phenotype at the right place within the valve structure and driving them towards homeostatic maintenance of the valve matrix. It is our hope and expectation that combinations of these new approaches with "old-fashioned" heart valve design would yield novel treatments for thousands of patients needing heart valve replacement.

\section{ACKNOWLEDGMENTS}

This work was funded in part by National Institutes of Health grants HL084194 (DS), HL097321 (JL), and Health Resources and Services Administration (DHHS R1CRH10429-01-00).

\section{CONFLICT OF INTEREST}

The authors indicated no potential conflicts of interest.

\section{REFERENCES}

[1] Lloyd-Jones D, Adams RJ, Brown TM, Carnethon M, Dai S, De Simone G, Ferguson TB, Ford E, Furie K, Gillespie C, Go A, Greenlund K, Haase N, Hailpern S, Ho PM, Howard V, Kissela B, Kittner S, Lackland D, Lisabeth L, Marelli A, McDermott MM, Meigs J, Mozaffarian D, Mussolino M, Nichol G, Roger VL, Rosamond W, Sacco R, Sorlie P, Stafford R, Thom T, Wasserthiel-Smoller S, Wong ND, Wylie-Rosett J. Executive summary: heart disease and stroke statistics - 2010 update: a report from the American Heart Association. Circulation. 2010, 121(7):948-54. 
[2] Lloyd-Jones D, Adams RJ, Brown TM, Carnethon M, Dai S, De Simone G, Ferguson TB, Ford E, Furie K, Gillespie C, Go A, Greenlund K, Haase N, Hailpern S, Ho PM, Howard V, Kissela B, Kittner S, Lackland D, Lisabeth L, Marelli A, McDermott MM, Meigs J, Mozaffarian D, Mussolino M, Nichol G, Roger VL, Rosamond W, Sacco R, Sorlie P, Thom T, Wasserthiel-Smoller S, Wong ND, WylieRosett J. Heart disease and stroke statistics-2010 update: a report from the American Heart Association. Circulation. 2010, 121(7):e46-e215.

[3] Goldbarg SH, Elmariah S, Miller MA, Fuster V. Insights into degenerative aortic valve disease. J Am Coll Cardiol. 2007, 50(13):1205-13.

[4] Yacoub M. Viewpoint: Heart valve engineering. Interview by James Butcher. Circulation. 2007,116(8):f44-6.

[5] Filova E, Straka F, Mirejovsky T, Masin J, Bacakova L. Tissue-engineered heart valves. Physiol Res. 2009 ,58 Suppl 2:S141-58.

[6] Hjortnaes J, Bouten CV, Van Herwerden LA, Grundeman PF, Kluin J. Translating autologous heart valve tissue engineering from bench to bed. Tissue Eng Part B Rev. 2009, 15(3):307-17.

[7] Sacks MS, Schoen FJ, Mayer JE. Bioengineering challenges for heart valve tissue engineering. Аnnu Rev Biomed Eng. 2009, 11:289-313.

[8] Mol A, Rutten MC, Driessen NJ, Bouten CV, Zund G, Baaijens FP, Hoerstrup SP. Autologous human tissue-engineered heart valves: prospects for systemic application. Circulation. 2006, 114(1 Suppl):I152-8.

[9] Mol A, Smits AI, Bouten CV, Baaijens FP. Tissue engineering of heart valves: advances and current challenges. Expert Rev Med Devices. 2009, 6(3):259-75.

[10] Baaijens F, Bouten C, Hoerstrup S, Mol A, Driessen N, Boerboom R. Functional tissue engineering of the aortic heart valve. Clin Hemorheol Microcirc. 2005, 33(3):197-9.

[11] Breuer CK, Mettler BA, Anthony T, Sales VL, Schoen FJ, Mayer JE. Application of tissue-engineering principles toward the development of a semilunar heart valve substitute. Tissue Eng. 2004, 10(1112):1725-36.

[12] Mol A, Bouten CV, Baaijens FP, Zund G, Turina MI, Hoerstrup SP. Review article: Tissue engineering of semilunar heart valves: current status and future developments. J Heart Valve Dis. 2004, 13(2):272-80.

[13] Mendelson K, Schoen FJ. Heart valve tissue engineering: concepts, approaches, progress, and challenges. Ann Biomed Eng. 2006, 34(12):1799-819.

[14] Gandaglia A, Bagno A, Naso F, Spina M, Gerosa G. Cells, scaffolds and bioreactors for tissue-engineered heart valves: a journey from basic concepts to contemporary developmental innovations. Eur J Cardiothorac Surg. 2011, 39(4):523-31.

[15] Jordan JE, Williams, J.K., Lee, S.J., Raghavan D., Atala, A.J., Yoo, J.J. In Situ Regeneration of Heart Valves: A Novel, Rapid Method for Tissue Engineering Heart Valves. The Western Thoracic Surgical Association. 2011.

[16] Sacks MS, Yoganathan AP. Heart valve function: a biomechanical perspective. Philos Trans R Soc Lond B Biol Sci. 2007, 362(1484):1369-91.

[17] Sacks MS, David Merryman W, Schmidt DE. On the biomechanics of heart valve function. J Biomech. 2009, 42(12):1804-24.

[18] Butcher JT, Simmons CA, Warnock JN. Mechanobiology of the aortic heart valve. J Heart Valve Dis. 2008, 7(1):62-73.

[19] Simionescu DT, Lovekamp JJ, Vyavahare NR. Degeneration of bioprosthetic heart valve cusp and wall tissues is initiated during tissue preparation: an ultrastructural study. J Heart Valve Dis. 2003, 12(2):226-34.

[20] Simionescu DT, Lovekamp JJ, Vyavahare NR. Glycosaminoglycan-degrading enzymes in porcine aortic heart valves: implications for bioprosthetic heart valve degeneration. J Heart Valve Dis. 2003, 12(2):217-25. 
[21] Simionescu DT, Lovekamp JJ, Vyavahare NR. Extracellular matrix degrading enzymes are active in porcine stentless aortic bioprosthetic heart valves. J Biomed Mater Res. 2003, 66A(4):755-63.

[22] Latif N, Sarathchandra P, Thomas PS, Antoniw J, Batten P, Chester AH, Taylor PM, Yacoub MH. Characterization of structural and signaling molecules by human valve interstitial cells and comparison to human mesenchymal stem cells. J Heart Valve Dis. 2007, 16(1):56-66.

[23] Ku CH, Johnson PH, Batten P, Sarathchandra P, Chambers RC, Taylor PM, Yacoub MH, Chester AH. Collagen synthesis by mesenchymal stem cells and aortic valve interstitial cells in response to mechanical stretch. Cardiovasc Res. 2006, 71(3):548-56.

[24] Taylor PM, Batten P, Brand NJ, Thomas PS, Yacoub MH. The cardiac valve interstitial cell. Int J Biochem Cell Biol. 2003, 35(2):113-8.

[25] Liu AC, Joag VR, Gotlieb AI. The emerging role of valve interstitial cell phenotypes in regulating heart valve pathobiology. Am J Pathol. 2007, 171(5):1407-18.

[26] Connolly JM, Alferiev I, Clark-Gruel JN, Eidelman N, Sacks M, Palmatory E, Kronsteiner A, Defelice S, Xu J, Ohri R, Narula N, Vyavahare N, Levy RJ. Triglycidylamine crosslinking of porcine aortic valve cusps or bovine pericardium results in improved biocompatibility, biomechanics, and calcification resistance: chemical and biological mechanisms. Am J Pathol. 2005, 166(1):1-13.

[27] Simionescu DT, Lu Q, Song Y, Lee JS, Rosenbalm TN, Kelley C, Vyavahare NR. Biocompatibility and remodeling potential of pure arterial elastin and collagen scaffolds. Biomaterials. 2006, 27(5):70213.

[28] Yip CY, Chen JH, Zhao R, Simmons CA. Calcification by valve interstitial cells is regulated by the stiffness of the extracellular matrix. Arterioscler Thromb Vasc Biol. 2009, 29(6):936-42.

[29] Engler AJ, Sen S, Sweeney HL, Discher DE. Matrix elasticity directs stem cell lineage specification. Cell. 2006, 126(4):677-89.

[30] Engler AJ, Sweeney HL, Discher DE, Schwarzbauer JE. Extracellular matrix elasticity directs stem cell differentiation. J Musculoskelet Neuronal Interact. 2007, 7(4):335.

[31] Hoerstrup SP, Kadner A, Melnitchouk S, Trojan A, Eid K, Tracy J, Sodian R, Visjager JF, Kolb SA, Grunenfelder J, Zund G, Turina MI. Tissue engineering of functional trileaflet heart valves from human marrow stromal cells. Circulation. 2002, 106(12 Suppl 1):I143-50.

[32] Schmidt D, Breymann C, Weber A, Guenter CI, Neuenschwander S, Zund G, Turina M, Hoerstrup SP. Umbilical cord blood derived endothelial progenitor cells for tissue engineering of vascular grafts. Ann Thorac Surg. 2004, 78(6):2094-8.

[33] Hoerstrup SP, Kadner A, Breymann C, Maurus CF, Guenter CI, Sodian R, Visjager JF, Zund G, Turina MI. Living, autologous pulmonary artery conduits tissue engineered from human umbilical cord cells. Ann Thorac Surg. 2002, 74(1):46-52.

[34] Sarugaser R, Ennis J, Stanford WL, Davies JE. Isolation, propagation, and characterization of human umbilical cord perivascular cells (HUCPVCs). Methods Mol Biol. 2009, 482:269-79.

[35] Wang HS, Hung SC, Peng ST, Huang CC, Wei HM, Guo YJ, Fu YS, Lai MC, Chen CC. Mesenchymal stem cells in the Wharton's jelly of the human umbilical cord. Stem Cells. 2004, 22(7):1330-7.

[36] Dvorin EL, Wylie-Sears J, Kaushal S, Martin DP, Bischoff J. Quantitative evaluation of endothelial progenitors and cardiac valve endothelial cells: proliferation and differentiation on poly-glycolic acid/poly-4-hydroxybutyrate scaffold in response to vascular endothelial growth factor and transforming growth factor beta1. Tissue Eng. 2003, 9(3):487-93.

[37] Villalona GA, Udelsman B, Duncan DR, McGillicuddy E, Sawh-Martinez RF, Hibino N, Painter C, Mirensky T, Erickson B, Shinoka T, Breuer CK. Cell-seeding techniques in vascular tissue engineering. Tissue Eng Part B Rev. 2010, 16(3):341-50.

[38] Pawlowski KJ, Rittgers SE, Schmidt SP, Bowlin GL. Endothelial cell seeding of polymeric vascular grafts. Front Biosci. 2004, 9:1412-21.

[39] Sagnella S, Anderson E, Sanabria N, Marchant RE, Kottke-Marchant K. Human endothelial cell interaction with biomimetic surfactant polymers containing Peptide ligands from the heparin binding domain of fibronectin. Tissue Eng. 2005, 11(1-2):226-36. 
[40] Bowlin GL, Meyer A, Fields C, Cassano A, Makhoul RG, Allen C, Rittgers SE. The persistence of electrostatically seeded endothelial cells lining a small diameter expanded polytetrafluoroethylene vascular graft. J Biomater Appl. 2001, 16(2):157-73.

[41] Ferrell N, Gallego-Perez D, Higuita-Castro N, Butler RT, Reen RK, Gooch KJ, Hansford DJ. Vacuumassisted cell seeding in a microwell cell culture system. Anal Chem. 2010, 82(6):2380-6.

[42] Hsu SH, Tsai IJ, Lin DJ, Chen DC. The effect of dynamic culture conditions on endothelial cell seeding and retention on small diameter polyurethane vascular grafts. Med Eng Phys. 2005, 27(3):267-72.

[43] Nasseri BA, Pomerantseva I, Kaazempur-Mofrad MR, Sutherland FW, Perry T, Ochoa E, Thompson CA, Mayer JE, Jr., Oesterle SN, Vacanti JP. Dynamic rotational seeding and cell culture system for vascular tube formation. Tissue Eng. 2003, 9(2):291-9.

[44] Perea H, Aigner J, Hopfner U, Wintermantel E. Direct magnetic tubular cell seeding: a novel approach for vascular tissue engineering. Cells Tissues Organs. 2006, 183(3):156-65.

[45] Shimizu K, Ito A, Arinobe M, Murase Y, Iwata Y, Narita Y, Kagami H, Ueda M, Honda H. Effective cell-seeding technique using magnetite nanoparticles and magnetic force onto decellularized blood vessels for vascular tissue engineering. J Biosci Bioeng. 2007, 103(5):472-8.

[46] van Wachem PB, Stronck JW, Koers-Zuideveld R, Dijk F, Wildevuur CR. Vacuum cell seeding: a new method for the fast application of an evenly distributed cell layer on porous vascular grafts. Biomaterials. 1990, 11(8):602-6.

[47] Steinhoff G, Stock U, Karim N, Mertsching H, Timke A, Meliss RR, Pethig K, Haverich A, Bader A. Tissue engineering of pulmonary heart valves on allogenic acellular matrix conduits: in vivo restoration of valve tissue. Circulation. 2000, 102(19 Suppl 3):III50-5.

[48] Konertz W, Dohmen PM, Liu J, Beholz S, Dushe S, Posner S, Lembcke A, Erdbrugger W. Hemodynamic characteristics of the Matrix P decellularized xenograft for pulmonary valve replacement during the Ross operation. J Heart Valve Dis. 2005, 14(1):78-81.

[49] Cebotari S, Mertsching H, Kallenbach K, Kostin S, Repin O, Batrinac A, Kleczka C, Ciubotaru A, Haverich A. Construction of autologous human heart valves based on an acellular allograft matrix. Circulation. 2002, 106(12 Suppl 1):I63-I8.

[50] Fang NT, Xie SZ, Wang SM, Gao HY, Wu CG, Pan LF. Construction of tissue-engineered heart valves by using decellularized scaffolds and endothelial progenitor cells. Chin Med J (Engl). 2007, 120(8):696-702.

[51] Lopes SA, Costa FD, Paula JB, Dhomen P, Phol F, Vilani R, Roderjan JG, Vieira ED. Decellularized heterografts versus cryopreserved homografts: experimental study in sheep model. Rev Bras Cir Cardiovasc. 2009, 24(1):15-22.

[52] Rieder E, Kasimir MT, Silberhumer G, Seebacher G, Wolner E, Simon P, Weigel G. Decellularization protocols of porcine heart valves differ importantly in efficiency of cell removal and susceptibility of the matrix to recellularization with human vascular cells. J Thorac Cardiovasc Surg. 2004, 127(2):399-405.

[53] Rieder E, Seebacher G, Kasimir MT, Eichmair E, Winter B, Dekan B, Wolner E, Simon P, Weigel G. Tissue engineering of heart valves: decellularized porcine and human valve scaffolds differ importantly in residual potential to attract monocytic cells. Circulation. 2005, 111(21):2792-7.

[54] Zhao DE, Li RB, Liu WY, Wang G, Yu SQ, Zhang CW, Chen WS, Zhou GX. Tissue-engineered heart valve on acellular aortic valve scaffold: in-vivo study. Asian Cardiovasc Thorac Ann. 2003, 11(2):1536.

[55] Gui L, Muto A, Chan SA, Breuer CK, Niklason LE. Development of decellularized human umbilical arteries as small-diameter vascular grafts. Tissue Eng Part A. 2009, 15(9):2665-76.

[56] Korossis SA, Booth C, Wilcox HE, Watterson KG, Kearney JN, Fisher J, Ingham E. Tissue engineering of cardiac valve prostheses II: biomechanical characterization of decellularized porcine aortic heart valves. J Heart Valve Dis. 2002, 11(4):463-71. 
[57] Simon P, Kasimir MT, Seebacher G, Weigel G, Ullrich R, Salzer-Muhar U, Rieder E, Wolner E. Early failure of the tissue engineered porcine heart valve SYNERGRAFT in pediatric patients. Eur $J$ Cardiothorac Surg. 2003, 23(6):1002-6.

[58] Williams C, Liao J, Joyce EM, Wang B, Leach JB, Sacks MS, Wong JY. Altered structural and mechanical properties in decellularized rabbit carotid arteries. Acta Biomater. 2009, 5(4):993-1005.

[59] Chuang TH, Stabler C, Simionescu A, Simionescu DT. Polyphenol-stabilized tubular elastin scaffolds for tissue engineered vascular grafts. Tissue Eng Part A. 2009, 15(10):2837-51.

[60] Gulbins H, Goldemund A, Anderson I, Haas U, Uhlig A, Meiser B, Reichart B. Preseeding with autologous fibroblasts improves endothelialization of glutaraldehyde-fixed porcine aortic valves. $J$ Thorac Cardiovasc Surg. 2003, 125(3):592-601.

[61] Gulbins H, Pritisanac A, Pieper K, Goldemund A, Meiser BM, Reichart B, Daebritz S. Successful endothelialization of porcine glutaraldehyde-fixed aortic valves in a heterotopic sheep model. Ann Thorac Surg. 2006, 81(4):1472-9.

[62] Moritz A, Grimm M, Eybl E, Grabenwoger M, Windberger U, Dock W, Bock P, Wolner E. Improved biocompatibility by postfixation treatment of aldehyde fixed bovine pericardium. ASAIO Trans. 1990, 36(3):M300-3.

[63] Weissenstein C, Human P, Bezuidenhout D, Zilla P. Glutaraldehyde detoxification in addition to enhanced amine cross-linking dramatically reduces bioprosthetic tissue calcification in the rat model. J Heart Valve Dis. 2000, 9(2):230-40.

[64] Sierad LN, Simionescu A, Albers C, Chen J, Maivelett J, Tedder ME, Liao J, Simionescu DT. Design and Testing of a Pulsatile Conditioning System for Dynamic Endothelialization of PolyphenolStabilized Tissue Engineered Heart Valves. Cardiovasc Eng Technol. 2010, 1(2):138-53.

[65] Tedder ME, Liao J, Weed B, Stabler C, Zhang H, Simionescu A, Simionescu DT. Stabilized collagen scaffolds for heart valve tissue engineering. Tissue Eng Part A. 2009, 15(6):1257-68.

[66] Booth C, Korossis SA, Wilcox HE, Watterson KG, Kearney JN, Fisher J, Ingham E. Tissue engineering of cardiac valve prostheses I: development and histological characterization of an acellular porcine scaffold. J Heart Valve Dis. 2002, 11(4):457-62.

[67] Stock UA, Schenke-Layland K. Performance of decellularized xenogeneic tissue in heart valve replacement. Biomaterials. 2006, 27(1):1-2.

[68] Karim N, Golz K, Bader A. The cardiovascular tissue-reactor: a novel device for the engineering of heart valves. Artif Organs. 2006, 30(10):809-14.

[69] Kasimir MT, Rieder E, Seebacher G, Nigisch A, Dekan B, Wolner E, Weigel G, Simon P. Decellularization does not eliminate thrombogenicity and inflammatory stimulation in tissue-engineered porcine heart valves. J Heart Valve Dis. 2006, 15(2):278-86. discussion 86.

[70] Kasimir MT, Rieder E, Seebacher G, Wolner E, Weigel G, Simon P. Presence and elimination of the xenoantigen gal (alpha1, 3) gal in tissue-engineered heart valves. Tissue Eng. 2005, 11(7-8):1274-80.

[71] Kasimir MT, Weigel G, Sharma J, Rieder E, Seebacher G, Wolner E, Simon P. The decellularized porcine heart valve matrix in tissue engineering: platelet adhesion and activation. Thromb Haemost. 2005, 94(3):562-7.

[72] Arai S, Lacerda C, Orton EC. Tissue-gel electrophoresis enhances antigen removal from porcine aortic valve and bovine pericardium. J Heart Valve Dis. 2010, 19(6):753-8.

[73] Bader A, Steinhoff G, Strobl K, Schilling T, Brandes G, Mertsching H, Tsikas D, Froelich J, Haverich A. Engineering of human vascular aortic tissue based on a xenogeneic starter matrix. Transplantation. 2000, 70(1):7-14.

[74] Tedder ME, Simionescu A, Chen J, Liao J, Simionescu DT. Assembly and testing of stem cell-seeded layered collagen constructs for heart valve tissue engineering. Tissue Eng Part A. 2011, 17(1-2):25-36.

[75] Matheny RG, Hutchison ML, Dryden PE, Hiles MD, Shaar CJ. Porcine small intestine submucosa as a pulmonary valve leaflet substitute. J Heart Valve Dis. 2000, 9(6):769-74.

[76] Vesely I. Heart valve tissue engineering. Circulation research. 2005, 97(8):743-55. 
[77] Butcher JT, Nerem RM. Porcine aortic valve interstitial cells in three-dimensional culture: comparison of phenotype with aortic smooth muscle cells. J Heart Valve Dis. 2004, 13(3):478-85.

[78] Butcher JT, Nerem RM. Valvular endothelial cells regulate the phenotype of interstitial cells in co-culture: effects of steady shear stress. Tissue Eng. 2006, 12(4):905-15.

[79] Jockenhoevel S, Zund G, Hoerstrup SP, Chalabi K, Sachweh JS, Demircan L, Messmer BJ, Turina M. Fibrin gel - advantages of a new scaffold in cardiovascular tissue engineering. Eur J Cardiothorac Surg. 2001, 19(4):424-30.

[80] Neidert MR, Tranquillo RT. Tissue-engineered valves with commissural alignment. Tissue Eng. 2006, 12(4):891-903.

[81] Ramamurthi A, Vesely I. Evaluation of the matrix-synthesis potential of crosslinked hyaluronan gels for tissue engineering of aortic heart valves. Biomaterials. 2005, 26(9):999-1010.

[82] Rothenburger M, Vischer P, Volker W, Glasmacher B, Berendes E, Scheld HH, Deiwick M. In vitro modelling of tissue using isolated vascular cells on a synthetic collagen matrix as a substitute for heart valves. Thorac Cardiovasc Surg. 2001, 49(4):204-9.

[83] Shi Y, Ramamurthi A, Vesely I. Towards tissue engineering of a composite aortic valve. Biomed Sci Instrum. 2002, 38:35-40.

[84] Taylor PM, Allen SP, Dreger SA, Yacoub MH. Human cardiac valve interstitial cells in collagen sponge: a biological three-dimensional matrix for tissue engineering. J Heart Valve Dis. 2002, 11(3):298-306.

[85] Taylor PM, Sachlos E, Dreger SA, Chester AH, Czernuszka JT, Yacoub MH. Interaction of human valve interstitial cells with collagen matrices manufactured using rapid prototyping. Biomaterials. 2006, 27(13):2733-7.

[86] Ye Q, Zund G, Benedikt P, Jockenhoevel S, Hoerstrup SP, Sakyama S, Hubbell JA, Turina M. Fibrin gel as a three dimensional matrix in cardiovascular tissue engineering. Eur J Cardiothorac Surg. 2000, 17(5):587-91.

[87] Flanagan TC, Wilkins B, Black A, Jockenhoevel S, Smith TJ, Pandit AS. A collagen-glycosaminoglycan co-culture model for heart valve tissue engineering applications. Biomaterials. 2006, 27(10):223346.

[88] Vesely I. The role of elastin in aortic valve mechanics. J Biomech. 1998, 31(2):115-23.

[89] Bense CA, Woodhouse KA. Plasmin degradation of fibrin coatings on synthetic polymer substrates. $J$ Biomed Mater Res. 1999, 46(3):305-14.

[90] Jackson MR, Alving BM. Fibrin sealant in preclinical and clinical studies. Curr Opin Hematol. 1999, 6(6):415-9.

[91] Jackson MR, MacPhee MJ, Drohan WN, Alving BM. Fibrin sealant: current and potential clinical applications. Blood Coagul Fibrinolysis. 1996, 7(8):737-46.

[92] Grassl ED, Oegema TR, Tranquillo RT. Fibrin as an alternative biopolymer to type-I collagen for the fabrication of a media equivalent. J Biomed Mater Res. 2002, 60(4):607-12.

[93] Murata K. Acidic glycosaminoglycans in human heart valves. J Mol Cell Cardiol. 1981, 13(3):281-92.

[94] Masters KS, Shah DN, Leinwand LA, Anseth KS. Crosslinked hyaluronan scaffolds as a biologically active carrier for valvular interstitial cells. Biomaterials. 2005, 26(15):2517-25.

[95] Flanagan TC, Cornelissen C, Koch S, Tschoeke B, Sachweh JS, Schmitz-Rode T, Jockenhoevel S. The in vitro development of autologous fibrin-based tissue-engineered heart valves through optimised dynamic conditioning. Biomaterials. 2007, 28(23):3388-97.

[96] Flanagan TC, Sachweh JS, Frese J, Schnoring H, Gronloh N, Koch S, Tolba RH, Schmitz-Rode T, Jockenhoevel S. In vivo remodeling and structural characterization of fibrin-based tissue-engineered heart valves in the adult sheep model. Tissue Eng Part A. 2009, 15(10):2965-76.

[97] Brody S, Pandit A. Approaches to heart valve tissue engineering scaffold design. J Biomed Mater Res B Appl Biomater. 2007, 83(1):16-43. 
[98] Pham QP, Sharma U, Mikos AG. Electrospinning of polymeric nanofibers for tissue engineering applications: a review. Tissue Eng. 2006, 12(5):1197-211.

[99] Sodian R, Hoerstrup SP, Sperling JS, Daebritz S, Martin DP, Moran AM, Kim BS, Schoen FJ, Vacanti JP, Mayer JE, Jr. Early in vivo experience with tissue-engineered trileaflet heart valves. Circulation. 2000, 102(19 Suppl 3):III22-9.

[100] Shinoka T, Breuer CK, Tanel RE, Zund G, Miura T, Ma PX, Langer R, Vacanti JP, Mayer JE, Jr. Tissue engineering heart valves: valve leaflet replacement study in a lamb model. Ann Thorac Surg. 1995, 60(6 Suppl):S513-6.

[101] Shinoka T, Ma PX, Shum-Tim D, Breuer CK, Cusick RA, Zund G, Langer R, Vacanti JP, Mayer JE, Jr. Tissue-engineered heart valves. Autologous valve leaflet replacement study in a lamb model. Circulation. 1996, 94(9 Suppl):II164-8.

[102] Shinoka T, Shum-Tim D, Ma PX, Tanel RE, Langer R, Vacanti JP, Mayer JE, Jr. Tissue-engineered heart valve leaflets: does cell origin affect outcome? Circulation. 1997, 96(9 Suppl):II-102-7.

[103] Ozawa T, Mickle DA, Weisel RD, Matsubayashi K, Fujii T, Fedak PW, Koyama N, Ikada Y, Li RK. Tissue-engineered grafts matured in the right ventricular outflow tract. Cell Transplant. 2004, 13(2):169-77.

[104] Nuttelman CR, Henry SM, Anseth KS. Synthesis and characterization of photocrosslinkable, degradable poly(vinyl alcohol)-based tissue engineering scaffolds. Biomaterials. 2002, 23(17):3617-26.

[105] Engelmayr GC, Jr., Rabkin E, Sutherland FW, Schoen FJ, Mayer JE, Jr., Sacks MS. The independent role of cyclic flexure in the early in vitro development of an engineered heart valve tissue. Biomaterials. 2005, 26(2):175-87.

[106] Hoerstrup SP, Sodian R, Sperling JS, Vacanti JP, Mayer JE, Jr. New pulsatile bioreactor for in vitro formation of tissue engineered heart valves. Tissue Eng. 2000, 6(1):75-9.

[107] Del Gaudio C, Bianco A, Grigioni M. Electrospun bioresorbable trileaflet heart valve prosthesis for tissue engineering: in vitro functional assessment of a pulmonary cardiac valve design. Ann Ist Super Sanita. 2008, 44(2):178-86.

[108] Courtney T, Sacks MS, Stankus J, Guan J, Wagner WR. Design and analysis of tissue engineering scaffolds that mimic soft tissue mechanical anisotropy. Biomaterials. 2006, 27(19):3631-8.

[109] Del Gaudio C, Grigioni M, Bianco A, De Angelis G. Electrospun bioresorbable heart valve scaffold for tissue engineering. Int J Artif Organs. 2008, 31(1):68-75.

[110] Dohmen PM, Konertz W. Tissue-engineered heart valve scaffolds. Ann Thorac Cardiovasc Surg. 2009, 15(6):362-7.

[111] Hong H, Dong GN, Shi WJ, Chen S, Guo C, Hu P. Fabrication of biomatrix/polymer hybrid scaffold for heart valve tissue engineering in vitro. ASAIO J. 2008, 54(6):627-32.

[112] Stankus JJ, Guan J, Fujimoto K, Wagner WR. Microintegrating smooth muscle cells into a biodegradable, elastomeric fiber matrix. Biomaterials. 2006, 27(5):735-44.

[113] Sodian R, Hoerstrup SP, Sperling JS, Martin DP, Daebritz S, Mayer JE, Jr., Vacanti JP. Evaluation of biodegradable, three-dimensional matrices for tissue engineering of heart valves. ASAIO J. 2000, 46(1):107-10.

[114] Sodian R, Sperling JS, Martin DP, Egozy A, Stock U, Mayer JE, Jr., Vacanti JP. Fabrication of a trileaflet heart valve scaffold from a polyhydroxyalkanoate biopolyester for use in tissue engineering. Tissue Eng. 2000, 6(2):183-8.

[115] Chen M, Patra PK, Warner SB, Bhowmick S. Role of fiber diameter in adhesion and proliferation of NIH 3T3 fibroblast on electrospun polycaprolactone scaffolds. Tissue Eng. 2007, 13(3):579-87.

[116] Li WJ, Mauck RL, Cooper JA, Yuan X, Tuan RS. Engineering controllable anisotropy in electrospun biodegradable nanofibrous scaffolds for musculoskeletal tissue engineering. J Biomech. 2007, 40(8):1686-93.

[117] Nerurkar NL, Elliott DM, Mauck RL. Mechanics of oriented electrospun nanofibrous scaffolds for annulus fibrosus tissue engineering. J Orthop Res. 2007, 25(8):1018-28. 
[118] Venugopal J, Low S, Choon AT, Ramakrishna S. Interaction of cells and nanofiber scaffolds in tissue engineering. J Biomed Mater Res B Appl Biomater. 2008, 84(1):34-48.

[119] Talman EA, Boughner DR. Internal shear properties of fresh porcine aortic valve cusps: implications for normal valve function. J Heart Valve Dis. 1996, 5(2):152-9.

[120] Talman EA, Boughner DR. Glutaraldehyde fixation alters the internal shear properties of porcine aortic heart valve tissue. Ann Thorac Surg. 1995, 60(2 Suppl):S369-73.

[121] Vesely I, Boughner D. Analysis of the bending behaviour of porcine xenograft leaflets and of natural aortic valve material: bending stiffness, neutral axis and shear measurements. Journal of Biomechanics. 1989, 22(6/7):655-71.

[122] Liao J, Joyce EM, Sacks MS. Effects of decellularization on the mechanical and structural properties of the porcine aortic valve leaflet. Biomaterials. 2008, 29(8):1065-74.

[123] Hoerstrup SP, Sodian R, Daebritz S, Wang J, Bacha EA, Martin DP, Moran AM, Guleserian KJ, Sperling JS, Kaushal S, Vacanti JP, Schoen FJ, Mayer JE, Jr. Functional living trileaflet heart valves grown in vitro. Circulation. 2000, 102(19 Suppl 3):III44-9.

[124] da Costa FD, Costa AC, Prestes R, Domanski AC, Balbi EM, Ferreira AD, Lopes SV. The early and midterm function of decellularized aortic valve allografts. Ann Thorac Surg. 2010, 90(6):1854-60.

[125] Lichtenberg A, Tudorache I, Cebotari S, Suprunov M, Tudorache G, Goerler H, Park JK, HilfikerKleiner D, Ringes-Lichtenberg S, Karck M, Brandes G, Hilfiker A, Haverich A. Preclinical testing of tissue-engineered heart valves re-endothelialized under simulated physiological conditions. Circulation. 2006, 114(1 Suppl):I559-65.

[126] Oswal D, Korossis S, Mirsadraee S, Wilcox H, Watterson K, Fisher J, Ingham E. Biomechanical characterization of decellularized and cross-linked bovine pericardium. J Heart Valve Dis. 2007, $16(2): 165-74$.

[127] Wang Q, McGoron AJ, Bianco R, Kato Y, Pinchuk L, Schoephoerster RT. In-vivo assessment of a novel polymer (SIBS) trileaflet heart valve. J Heart Valve Dis. 2010, 19(4):499-505.

[128] Ingber DE. Tensegrity: the architectural basis of cellular mechanotransduction. Annu Rev Physiol. 1997, 59:575-99.

[129] Maul TM, Chew DW, Nieponice A, Vorp DA. Mechanical stimuli differentially control stem cell behavior: morphology, proliferation, and differentiation. Biomech Model Mechanobiol. 2011, 10:939953.

[130] Yamamoto K, Takahashi T, Asahara T, Ohura N, Sokabe T, Kamiya A, Ando J. Proliferation, differentiation, and tube formation by endothelial progenitor cells in response to shear stress. J Appl Physiol. 2003, 95(5):2081-8.

[131] Schumann D, Kujat R, Nerlich M, Angele P. Mechanobiological conditioning of stem cells for cartilage tissue engineering. Biomed Mater Eng 2006.16(4 Suppl):S37-52.

[132] Jacot JG, Martin JC, Hunt DL. Mechanobiology of cardiomyocyte development. J Biomech. 2010, 43(1):93-8.

[133] Sabbah HN, Hamid MS, Stein PD. Mechanical factors in the degeneration of porcine bioprosthetic valves: an overview. J Card Surg. 1989, 4(4):302-9.

[134] Haziza F, Papouin G, Barratt-Boyes B, Christie G, Whitlock R. Tears in Bioprosthetic Heart Valve Leaflets without Calcific Degeneration. Journal of Heart Valve Disease. 1996, 5:35-9.

[135] Grabenwoger M, Fitzal F, Gross C, Hutschala D, Bock P, Brucke P, Wolner E. Different modes of degeneration in autologous and heterologous heart valve prostheses. J Heart Valve Dis. 2000, 9(1):104-9.

[136] Rao KP, Shanthi C. Reduction of calcification by various treatments in cardiac valves. J Biomater Appl. 1999, 13(3):238-68.

[137] Schoen FJ. Pathology of heart valve substitution with mechanical and tissue prostheses. In: Silver MD, Gotlieb AI, Schoen FJ, editors. Cardiovascular Pathology. New York: Livingstone. 2001. 
[138] Liao J, Joyce EM, Merryman WD, Jones HL, Tahai M, Horstemeyer MF, Williams LN, Hopkins RA, Sacks MS. The Intrinsic Fatigue Mechanism of the Porcine Aortic Valve Extracellular Matrix. Cardiovascular Engineering and Technology 2012.Epub Date: January 7.

[139] Grande-Allen KJ, Liao J. The heterogeneous biomechanics and mechanobiology of the mitral valve: implications for tissue engineering. Curr Cardiol Rep. 2011, 13(2):113-20.

[140] Schoen FJ. Heart valve tissue engineering: quo vadis? Curr Opin Biotechnol. 2011, 22(5):698-705. 


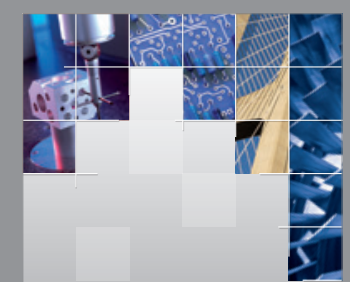

\section{Enfincering}
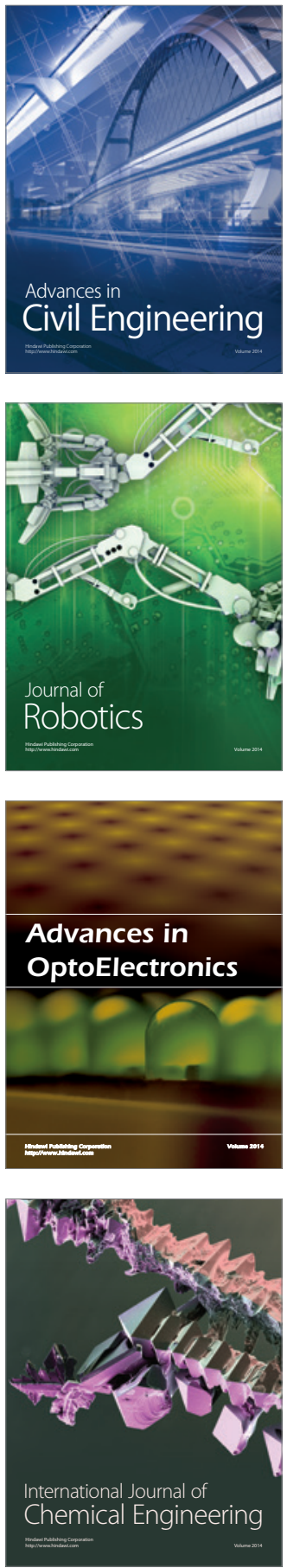



The Scientific World Journal

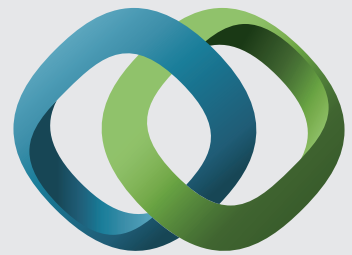

\section{Hindawi}

Submit your manuscripts at

http://www.hindawi.com
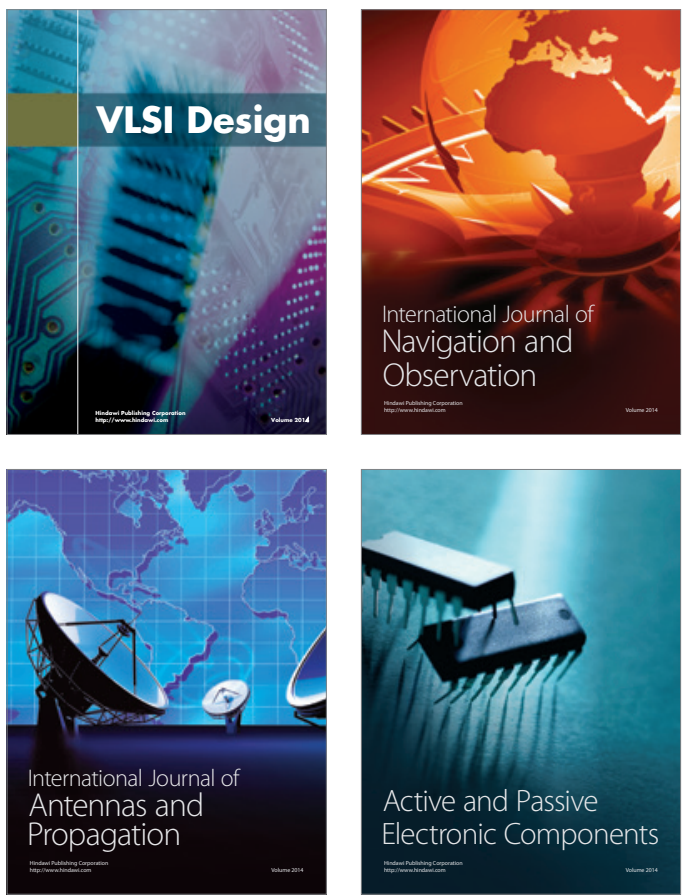
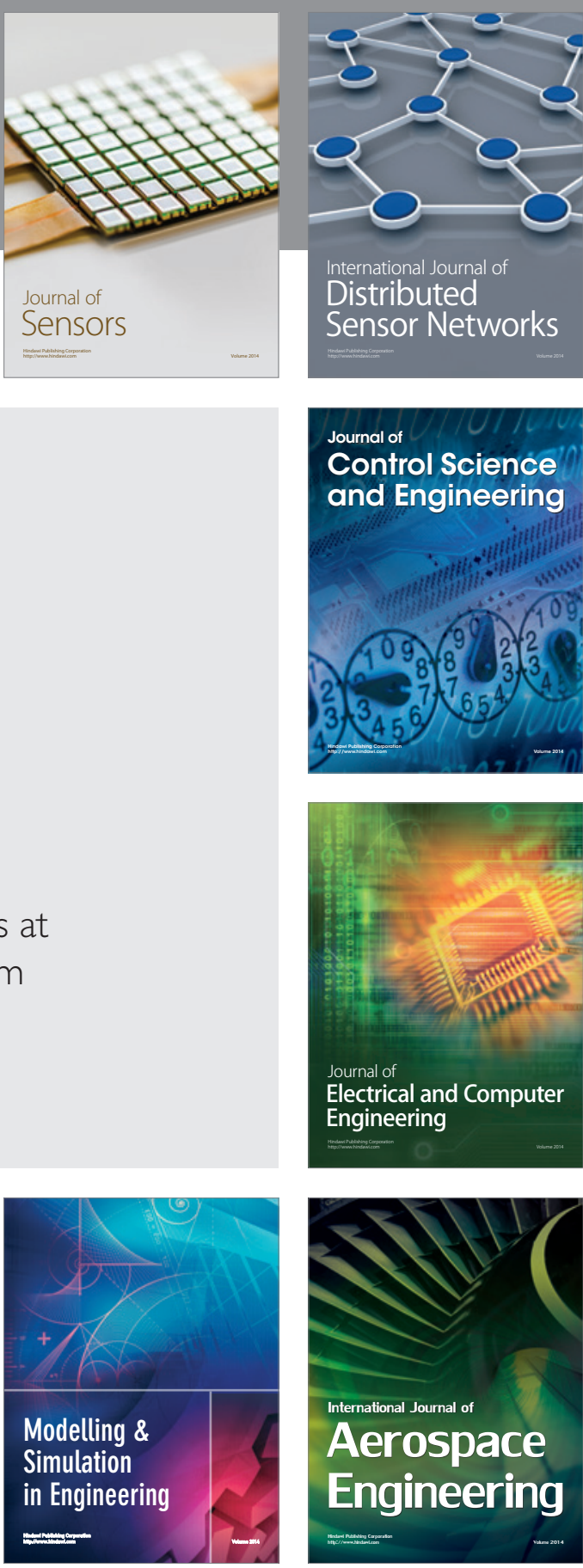

International Journal of

Distributed

Sensor Networks

Journal of

Control Science

and Engineering
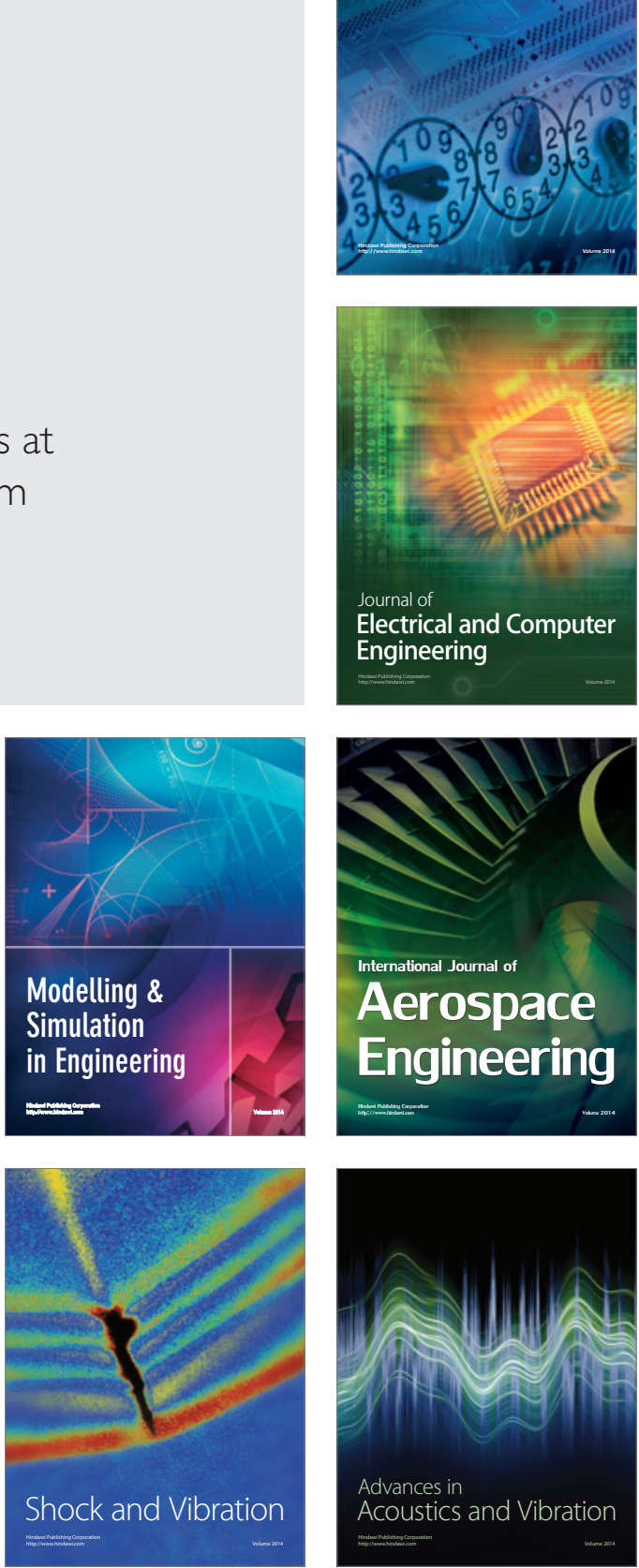